\title{
To what extent can online mapping be decolonial? A journey throughout Indigenous cartography in Canada
}

\author{
Thomas J. McGurk \\ Department of Geography, Concordia University \\ Sébastien Caquard \\ Department of Geography, Concordia University
}

\section{Key Messages}

- Indigenous online mapping projects address similar issues as conventional GIS projects but use a form of expression better aligned with Indigenous perspectives.

- Indigenous communities are highly involved in the data-sharing process for these projects, while technological aspects remain under the direction of non-Indigenous partners.

- These websites do not leave much room for women's perspectives, but these voices seem to be playing a growing role in framing contemporary Indigenous mapping practices.

In this paper, we describe and reflect upon our journey through Indigenous online mapping in Canada. This journey has been planned according to an academic goal: assessing the potential of online cartography for decolonial purposes. To reach this goal, we have followed methodological directions provided by Indigenous scholar Linda Tuhiwai Smith to review 18 Indigenous web-mapping sites across Canada. Supported by a series of ten interviews, this content analysis enabled us to sketch some of the contours of contemporary Indigenous cartography. On one hand, Indigenous communities largely control the data that are shared on these websites. They also partially control the way these data are represented through the mobilization of digital storytelling technologies that are better aligned with Indigenous ways of envisioning relationships to places than conventional maps. On the other hand, they do not have much control over the technological aspects of these projects, for which they remain heavily dependent on non-Indigenous partners. Throughout this journey, we noticed that women's voices remained marginal in most of these mapping projects, but we also identified evidence supporting the idea that these voices are starting to play a vital role in the on-going effort of decolonizing mapping processes.

Keywords: Indigenous, cartography, web mapping, decolonized, Canada

\section{La cartographie sur Internet peut-elle être un instrument de décolonisation? Regards sur la cartographie autochtone au Canada}

Dans cet article, nous proposons une réflexion sur la cartographie autochtone sur Internet au Canada. Cette réflexion est structurée autour d'un objectif universitaire: évaluer le potentiel cartographique contemporain à des fins de décolonisation. Pour atteindre cet objectif, nous avons utilisé un cadre méthodologique développé par la chercheuse autochtone Linda Tuhiwai Smith pour étudier 18 sites Web autochtones de cartographie au Canada. Appuyée par une série de dix entrevues, cette étude nous a permis d'esquisser les grandes lignes de la

Correspondence to / Adresse de correspondance: Thomas McGurk, Department of Geography, Concordia University, 1455 De Maisonneuve Blvd. W., S-H 1255-31, Montreal, QC H3G 1M8. Email/Courriel: tmcgurk1817@gmail.com 
cartographie autochtone contemporaine. D'une part, les communautés autochtones semblent contrôler largement les données présentées sur ces sites Web, ainsi que la manière d'exprimer leurs relations aux lieux à l'aide de technologies de narration numérique plutôt qu'à l'aide de cartes conventionnelles. En revanche, les communautés autochtones restent largement dépendantes de partenaires non autochtones pour la gestion des aspects technologiques de ces projets. Finalement, nous avons remarqué une marginalisation de la voix des femmes dans la plupart de ces projets cartographiques, tout en identifiant certains changements récents qui laissent à penser que ces voix féminines vont très rapidement jouer un rôle déterminant dans cet effort de décolonisation du processus cartographique.

Mots clés : autochtone, cartographie, cartographie numérique, décolonisation, Canada

\section{Introduction}

On June 21, 2017, Google made headlines across Canada by announcing that more than 3,000 Indigenous communities in Canada have been added to Google Maps and Google Earth, as part of the $150^{\text {th }}$ anniversary of the Canadian confederation. That day, in a news report from the Canadian Broadcasting Corporation (CBC 2017), a prominent Indigenous cartographer who collaborated with Google on this project for several years was demonstrating this new mapping feature in Winnipeg, in front of a Petro-Canada gas station where the "Long Plain Madison Indian Reserve No.1" is located. While this news report was celebrating the major step that this new cartographic feature represents for the recognition of the historical and contemporary Indigenous presence in Canada, the celebratory tone was somewhat counterbalanced by the example used to illustrate the relevance of this new feature for Indigenous people and for reconciliation: a tiny Indian reserve located in a commercial suburb emblematized by a Petro-Canada gas station.

The scepticism about the real influence of such a mapping feature for Indigenous empowerment was reinforced by the difficulty of visualizing more than one of these Indigenous communities (i.e., Indian reserves) at once on Google Maps. This relative invisibility of Indigenous territories on Google Maps contrasts with the high visibility offered by other online mapping projects dedicated to representing these territories. There is, for instance, the case of the native-land.ca project in which Turtle Island (i.e., North America, Earth) appears filled with overlapping polygons materializing the extent of historical Indigenous lands and languages (see Figure 1). On the one hand, the native-land.ca example characterizes the potential that online mapping holds for bringing to the fore the extent of original and claimed Indigenous territories and the cultures associated with them. On the other hand, the previous example of Google Maps illustrates the ongoing Western cartographic framing of these issues through the use of the latest Western cartographic technologies mobilized to represent state-approved territories, thereby perpetuating the imposition of Western worldviews on Indigenous lands and cultures (Pearce and Louis 2008; Turnbull 2008; Wainwright and Bryan 2009; Louis et al. 2012; Vermeylen et al. 2012; Reid and Sieber 2019). Beyond these two examples, we set out to study the extent to which online mapping applications have been mobilized by Indigenous communities across Canada to advance their own territorial, social, and cultural agendas.

To reach this goal, we developed a methodology inspired by the work of Indigenous scholar Linda Tuhiwai Smith to assess the decolonizing dimensions of Indigenous online mapping projects. We applied this methodology to 18 Indigenous online mapping projects identified across Canada. The results of this assessment are presented and discussed critically through the light of ten semistructured interviews done with individuals with Indigenous and non-Indigenous backgrounds who were involved in Indigenous mapping projects. We conclude this paper by highlighting some of the most inspirational traits and characteristics found in these websites to emphasize certain potentialities and limits of online cartography for decolonial mapping purposes.

Before moving to the next section, it is essential to mention that this assessment is made from the perspective of two non-Indigenous academics interested in trying to understand better how Indigenous communities engage with the potentials and limits offered by online mapping applications. Given this positionality, we have tried to remain as careful as we can be every time we engage with Indigenous related 

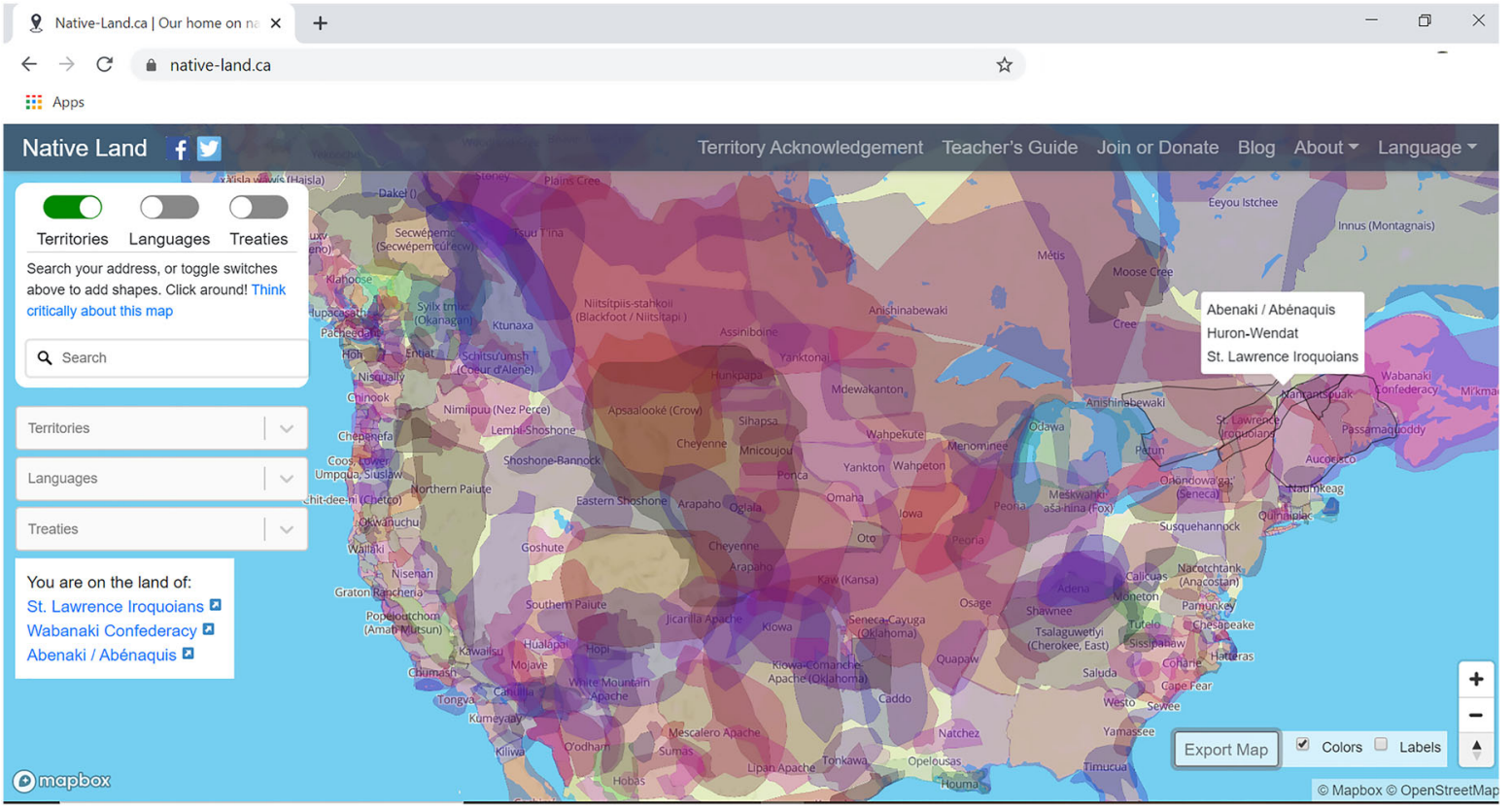

\section{Figure 1}

Screen capture of the map of the native-land project. The overlapping polygons represent the extent of First Nations territories and characterize the complexity of these entangled territories.

SOURCE: https://native-land.ca/.

issues but we recognize that this positionality limits our full understanding of certain aspects of Indigenous mapping.

\section{Indigenous online (counter) mapping}

In her review of the history of Indigenous mapping, Annita Lucchesi $(2018,13)$ identifies Indigenous "ancestral mapping" as encompassing "any mapping or cartographic praxes developed by Indigenous ancestors who were not explicitly engaging with colonialism in their cartography." These praxes took a range of forms, from carvings on trees and sewing Wampum belts to the use of oral stories as means of wayfinding and spatial ordering (Pearce and Louis 2008; Cameron 2011; Hunt and Stevenson 2017). Lucchesi argues that Indigenous people pioneered this genre of mapping that tells people's stories and describes people's relationships to places and other beings, but those ancestral modes of spatial expressions were deeply affected by the arrival of the Europeans.
Mapmaking has been identified as one of the first modes of communication between autochthones and allochthones who lacked a common language (Eades 2015), but this mode of communication did not imply a dialogue or a mutually rewarding and fulfilling discourse. As the power and popularity of maps became entrenched in colonial culture, maps and mapping drifted away from their use as a common language to become a tool for the imposition of a Eurocentric cosmovision: a worldview rooted in an economic system that envisioned land and resources not being used according to what colonizers perceived as their fullest extent as being unclaimed, unproductive, and therefore wasted. This idea of a "terra nullius" waiting for development was supported by maps of large blank spaces that portrayed North America (and other parts of the world) as an empty territory open for appropriation and exploitation. Maps became a powerful tool of territorial dispossession of Indigenous people in North America and throughout the entire colonized world (Reynolds 2003; Attwood 2004; Banner 2005; 
Cavanagh 2014; Borrows 2015; Bryan and Wood 2015). In a few decades, mapmaking moved from being a mode of communication to becoming a tool of dispossession.

According to Eades (2015), this metamorphosis revealed two vastly different worldviews: while Indigenous persons were "mapping," which is a processoriented activity indicative of an Indigenous way of seeing, Europeans were "mapmaking," which is an object-focused activity that reflects a Eurocentric worldview. This distinction between mapping and mapmaking draws support from Rundstrom (1991), who argued that non-text-based peoples place more value on the process while text-based peoples place more value on the product. This distinction was further developed by Bjorn Sletto (2014), who argued that a post-representational perspective on mapping would be better aligned with Indigenous mapping practices since it values process, memory, and performance over the product. Sletto also builds upon an argument made by Margaret Wickens Pearce (2008), who contends that when maps are seen as processes, it opens the doors to more experimental forms of mapping that can better mobilize the strengths of oral and performative formats as a means of transmission of Indigenous knowledge.

Since European colonization, Indigenous mapping has had to move back and forth between ancestral and processual mapping and the colonizers' requirements for precise, standardized, and rational mapmaking practices. While these requirements have been detrimental over the centuries for Indigenous communities, Indigenous groups have learned how to master Western mapmaking techniques to push forward their territorial and political agendas and to start (re) using maps as forms of spatial claims. For instance, in Canada, Inuit people were highly involved in mapmaking activities as part of the Inuit Land Use and Occupancy Project (ILUOP) that started in the 1970 s, and led to the creation of the Inuit territory of Nunavut (Usher 2003; Bryan and Wood 2015). One exciting aspect of this project was that the mapped information was recollection-based; it used historical narratives, traditional place names, and traditional Indigenous knowledge in their construction. In other words, this project was structured around Western mapmaking practices, as a way to express the historical, cultural, and survival attachment of Inuit people to the land. These relationships to the territory were expressed through memories, recollections, stories, and map biographies. In this case, Western mapmaking practices were infused with Indigenous mapping approaches and processes.

In the contemporary context of online cartography, Western technologies have also been appropriated by Indigenous groups and individuals and infused with Indigenous knowledge (Caquard et al. 2009; Pyne and Taylor 2012; Corbett et al. 2015; Thom et al. 2016; Pyne 2020). For instance, DeRoy (2016) and Olson et al. (2016) argue that the method called direct-to-digital mapping, which consists of collecting and sharing data and stories using mainstream digital technologies such as GPS and Google Earth, has become quite popular in Indigenous communities since it enables members of these communities to control the process as well as the content. It also opens new possibilities for stories to be told, geolocated, and shared. Storytelling remains a significant aspect of many Indigenous cultures (McIvor 2010; Drawson et al. 2017), and digital media gives the power to Indigenous groups and individuals to control these stories and to share them broadly (Cunsolo Willox et al. 2013; de Jager et al. 2017; Eglinton et al. 2017). Given the popularity of online mapping tools within Indigenous communities, and given the potential these tools offer to better control the mapping process from data collection to spatial expression, it seems logical to draw conclusions that online mapping applications may offer real opportunities to advance Indigenous decolonial mapping agenda. In the rest of this paper, we propose to study how this assumption reifies within the Canadian context.

\section{A methodology inspired by "decolonized methodologies"}

Methodology is important because it frames the questions being asked, determines the set of instruments and methods to be employed, and shapes the analyses. Within an Indigenous framework, methodological debates are ones concerned with the broader politics and strategic goals of Indigenous research. It is at this level that researchers have to clarify and justify their intentions. (Smith 2013, 144)

As mentioned previously, the primary intention of this project is academic; it is to better understand the 
extent to which online mapping technologies in Canada have been mobilized to advance a decolonial mapping agenda. Beyond this main endeavour, a secondary objective is to contribute to making visible Indigenous mapping initiatives that could be inspirational for us and others. To reach these goals, we devised a systematic review of online Indigenous mapping projects in Canada. A twofold process informed this analysis. The first phase of the work consisted of a website content review, while the second phase relied on interviews with map producers, users, and project participants to help make sense of the review. Both approaches were done in parallel and were selected to gather a range of data and perspectives. The website review systematically captured data to provide a baseline description of the types of Indigenous online mapping projects occurring in Canada. Comments and thoughts derived from the interviews served to orient, deepen, support, and challenge our reading of these results and our understanding of Indigenous online mapping. In the context of this work, "online mapping" refers to any forms of spatial expression designed with online mapping applications such as Google Maps, OpenStreetMap, Nunaliit, Google Earth, Carto, and ESRI Story Maps; we are not referring to digital versions of maps that were not produced with an online mapping application, for example, PDF versions of maps produced with a Geographic Information System (GIS).

The selection of the websites was based on three criteria: (1) being associated with Canada; (2) addressing Indigenous issues; and (3) including maps designed for the web, such as animated or interactive maps (i.e., not digital versions of paper maps). Based on these criteria, an initial list of potential Indigenous mapping websites was culled, and a total of 18 websites were identified during the spring of 2017 (see Table 2).

The content analysis of these websites centred on a methodological framework developed and visualized by Indigenous scholar Linda Tuhiwai Smith $(2013,113)$, who draws from the culture of Pacific Islanders and their metaphor of the tidal pool to construct an Indigenous research agenda. The pool and its overlapping and intermingling waves acting upon individuals in the environment is intended to help visualize various concepts that impact the creation of knowledge. A mix of processes and conditions defines her model of a decolonialized research agenda. The processes are conceptualized as the waves spreading across a pool, from the local to the global in four cardinal directions (mobilization, healing, decolonization, and transformation). The conditions refer to states of being through which peoples, groups, or communities are moving during the process of research (from the states of survival to the states of self-determination).

Within her work, Smith (2013) identifies 25 decolonialized project types. Included within the list is "land claiming," which encourages Indigenous people to make others aware of their rights and what is due to them. Also included are "storytelling" and "remembering"-both considered integral parts of Indigenous culture. Others included are "gendering" and "Indigenized processes"; the latter can enable Indigenous people to take control of the discourse related to their issues and perspectives. For our work, Smith's proposed 25 decolonized project types were adapted to allow us to study more specifically the Indigenous online mapping projects, resulting in a series of 21 criteria organized under 7 meta-criteria (see Table 3). Operationally, the content analysis consisted of individually reviewing each of the 18 websites in the study and identifying content associated with each of these 21 criteria.

The first step was to identify all the content associated with each site. This identification was partially automated using link scraping plugins (Link Grabber and Link Klipper), which provided us with a list of links within and out of a given site (i.e., internal and external links). The use of a scraper in this manner provided a relatively comprehensive list of the links for each site. However, the use of any single scraper or application programming interface does not guarantee a complete list, so a manual inspection of each site was also necessary. The second part of the process was more labourintensive as it required reviewing the content of all the pages linked to each website and assessing if its content could be associated with one or more of the 21 criteria mobilized. This process enabled us to make sure we reviewed the entire content of each website, including external links, and allowed us to provide evidence related to each of the criteria under study. A running tally sheet was then marked indicating the type of content identified, the associated criteria, and the url where it 
was found. To illustrate this process, each time a place name appeared on a map in its original Indigenous language, it was considered under "traditional naming" (see Figure 2). If it was associated with a story related to this place, it was also considered as "cultural narrative." If a woman told this story, or if the content related to the linked information addressed what have historically been the unheard voices of women, it was also considered as "gendered," etc.

It should be noted that the content analysis for all the traits being assessed in this work is multivariate. For example, as it relates to "gendered" content, the reviewer was able to consider who had created the content, was it a man or a woman? Is the author Indigenous? Is the source of information from a media account or firsthand observation and experience? Is the content giving voice to an issue that has historically been ignored or uninvestigated? In other words, no single characteristic of the content was used to define it as being one thing or another. Using a multivariate approach and viewing the content holistically, in its context, allowed the reviewer a degree of discretion that would not have been possible with a more rigid or "check-list" form of analysis. The results of this analysis are synthesized in Table 3.

This systematic and quantified review of the content of these websites was completed by a series of ten qualitative interviews done with participants selected because of their interest and involvement with Indigenous mapping either as an Indigenous person, a cartographer, a scholar, or all of the above (see Table 1). The interview process was semi-structured. A list of 13 questions was prepared, but participants were given considerable latitude in the issues they wished to address or not address in their responses. Most interviews were between 45 and 60 minutes in length. The main goal of these interviews was to guide our content analysis of the data gathered and to better integrate Indigenous voices and perspectives, following the recommendations of Renee Pualini Louis (2007), in a process that remained highly influenced by Western academic culture.
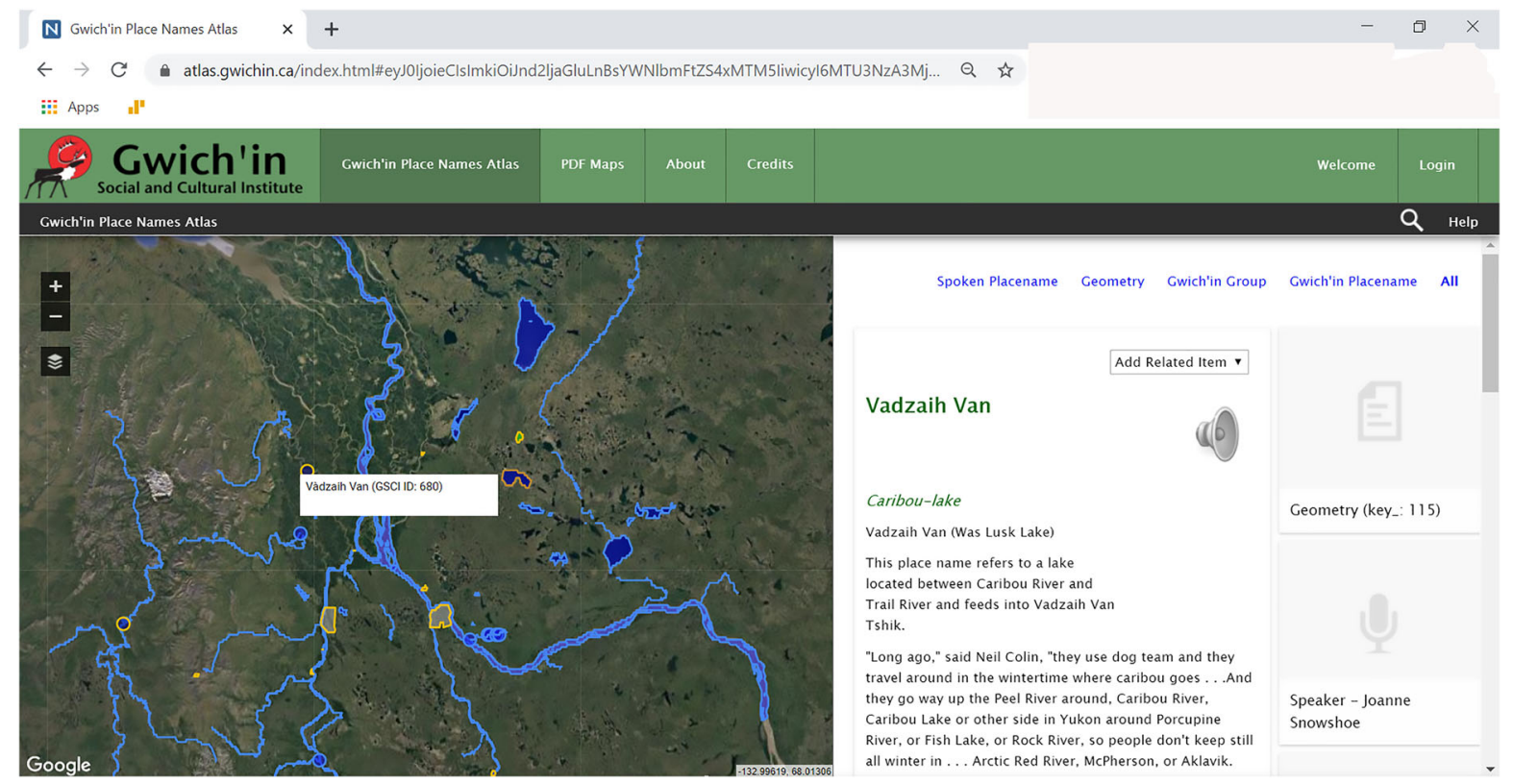

\section{Figure 2}

Incident definition: Clicking the link on the map to the left takes the viewer to the content on the right. In this example, this particular place name was considered under "place naming" as well as "cultural narrative" since it is associated with historical stories about caribous. SOURCE: https://atlas.gwichin.ca. 
Table 1

Participant interview composition based on self-determination.

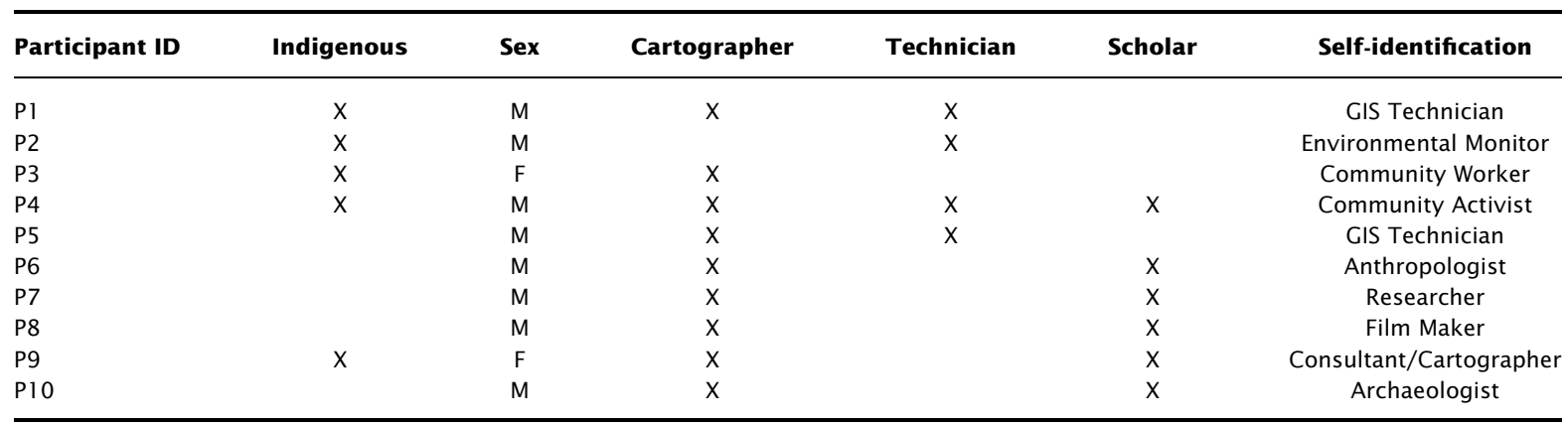

\section{Results}

When we look at the overall results of this review, the first observation is that a majority of the 21 decolonizing criteria assessed in this study are identified extensively in most of the websites, as indicated by the appearance of the value " $\mathrm{H}$ " in Table 3. The notation "H" stands for "High" and means that the criteria have been identified more than five times on the website. "M," which stands for "Marginal" means that the criteria have been identified five times or less, and a blank cell means that it has not been identified at all. (Note: The list of websites associated with each letter is available in Table 2; the values appear in Table 3).

Table 3 also shows is that there are some critical variations between criteria and between the websites reviewed. For instance, if we look at the two ends of this spectrum, The "Oka Crisis": A Digital Atlas of the 1990 Events at Kanehsatà:ke (website A) integrates all of the traits and criteria studied in this review, while in Thule Atlas (website R), only three of the criteria have been identified as " $\mathrm{H}$ " and five as "M." These differences are explained by the fact that some of these atlases focus on one particular aspect of Indigenous culture. Indeed, the Thule Atlas is an excellent example of a project led by an Indigenous organization (Kitikmeot Heritage Society) in collaboration with a research centre (the Geomatics and Cartographic Research Centre at Carleton University), to digitally return the Inuit material collected between 1921 and 1924 by the fifth Thule expedition in Nunavut (https:// thuleatlas.org). Although this project is very particular in its scope, it stands out because of the cultural, historical, and political aspects of the mapping of this expedition and the artifacts collected. In other words, a website in which only a few study criteria have been identified can be as meaningful and powerful as a project that meets more criteria.

\section{Controlling (most of) the mapping process}

The control of the different steps of the entire process of online mapping by Indigenous communities is undoubtedly a vital factor of any decolonizing mapping project. Indigenous communities appear to be involved in most of the projects studied. The link counts and the content identified during the counts in most of the cases indicate affiliations with Indigenous communities, bands, or groups of nations and that the content generated came from Indigenous persons or from an Indigenous perspective. It must be noted that these websites have been designed in collaboration with non-Indigenous partners; two academic partners and one non-governmental organization were identified. The academic partners are the Geomatics and Cartographic Research Centre at Carleton University, which is involved in eight websites, and the Ethnographic Mapping Lab at the University of Victoria, which is involved in six websites. Ecotrust Canada, a non-governmental organization (NGO), is involved in two websites. One of the two remaining websites, the Squamish Atlas (http://squamishatlas.com/), was developed by the Indigenous non-profit Kwi Awt Stelmexw in collaboration with Victor Temprano, a self-defined "settler" web developer. Temprano also created the other website not affiliated with a university or an NGONative Land (https://native-land.ca/about/). 
Table 2

List of websites reviewed.

\begin{tabular}{|c|c|c|c|c|}
\hline A & $\begin{array}{l}\text { The "Oka Crisis": A Digital Atlas of } \\
\text { the } 1990 \text { Events at Kanehsatà:ke }\end{array}$ & $\begin{array}{l}\text { http://www.uvic.ca/socialsciences/ethnographicmapping/ } \\
\text { projects/oka/index.php }\end{array}$ & & $\begin{array}{l}\text { Ethnographic } \\
\text { Mapping Lab }\end{array}$ \\
\hline B & $\begin{array}{l}\text { Nuu-chah-nulth First Nations in } \\
\text { Clayoquot Sound }\end{array}$ & http://livingatlas.org & $\begin{array}{l}\text { Nuu-chah-nulth First } \\
\text { Nations }\end{array}$ & Ecotrust.ca \\
\hline D & Okanagan Nation Alliance & http://voicesontheland.org/index.html & $\begin{array}{l}\text { Okanagan Nation } \\
\text { Alliance }\end{array}$ & Ecotrust.ca \\
\hline $\mathrm{F}$ & Native Land & https://native-land.ca/ & & \\
\hline G & Stz'uminus Storied Places & $\begin{array}{l}\text { http://www.uvic.ca/socialsciences/ethnographicmapping/ } \\
\text { projects/stzuminus/index.php }\end{array}$ & $\begin{array}{l}\text { Stz'uminus First } \\
\text { Nation }\end{array}$ & $\begin{array}{l}\text { Ethnographic } \\
\text { Mapping Lab }\end{array}$ \\
\hline $\mathrm{H}$ & SquamishAtlas.com & $\begin{array}{l}\text { http://squamishatlas.com/ (Formerly: } \\
\text { http://ohtheplacesyoushouldknow.com/) }\end{array}$ & KAS Cultural Society & \\
\hline 1 & Gwich'in Place Names Atlas & http://atlas.gwichin.ca/index.html & $\begin{array}{l}\text { Gwich'in Social and } \\
\text { Cultural Institute }\end{array}$ & $\begin{array}{l}\text { Geomatics and } \\
\text { Cartographic } \\
\text { Research Centre }\end{array}$ \\
\hline L & Arctic Bay Atlas & http://arcticbayatlas.ca/index.html & $\begin{array}{l}\text { Nunavut Youth } \\
\text { Consulting }\end{array}$ & $\begin{array}{l}\text { Geomatics and } \\
\text { Cartographic } \\
\text { Research Centre }\end{array}$ \\
\hline M & Kitikmeot Place Name Atlas & http://atlas.kitikmeotheritage.ca & $\begin{array}{l}\text { Kitikmeot Heritage } \\
\text { Society }\end{array}$ & $\begin{array}{l}\text { Geomatics and } \\
\text { Cartographic } \\
\text { Research Centre }\end{array}$ \\
\hline $\mathrm{N}$ & Cartographic legacies & $\begin{array}{c}\text { http://www.uvic.ca/socialsciences/ethnographicmapping/ } \\
\text { projects/cartographic-legacies/index.php }\end{array}$ & Coast Salish peoples & $\begin{array}{l}\text { Ethnographic } \\
\text { Mapping Lab }\end{array}$ \\
\hline $\mathrm{O}$ & $\begin{array}{l}\text { Mapping contemporary challenges } \\
\text { to island Hul'qumi'num peoples' } \\
\text { territories }\end{array}$ & https://sites.google.com/view/htgcasestudy/ & $\begin{array}{l}\text { Hul'qumi'num Treaty } \\
\text { Group }\end{array}$ & $\begin{array}{l}\text { Ethnographic } \\
\text { Mapping Lab }\end{array}$ \\
\hline$P$ & Coast Salish cultural landscapes & $\begin{array}{c}\text { http://www.uvic.ca/socialsciences/ethnographicmapping/ } \\
\text { projects/cultural-landscapes/index.php }\end{array}$ & $\begin{array}{l}\text { Coast Salish cultural } \\
\text { landscapes }\end{array}$ & $\begin{array}{l}\text { Ethnographic } \\
\text { Mapping Lab }\end{array}$ \\
\hline
\end{tabular}


Table 2

(Continued)

\begin{tabular}{|c|c|c|c|c|}
\hline Q & Pan Inuit Trails Map & http://paninuittrails.org/index.html & $\begin{array}{l}\text { Inuit occupancy of } \\
\text { the Northwest } \\
\text { Passage }\end{array}$ & $\begin{array}{l}\text { Geomatics and } \\
\text { Cartographic } \\
\text { Research Centre }\end{array}$ \\
\hline $\mathrm{R}$ & Fifth Thule Expedition Atlas & https://thuleatlas.org/index.html & $\begin{array}{l}\text { Kitikmeot Heritage } \\
\text { Society }\end{array}$ & $\begin{array}{l}\text { Geomatics and } \\
\text { Cartographic } \\
\text { Research Centre }\end{array}$ \\
\hline
\end{tabular}

Table 3

Synthesis of the review of the 21 criteria (rows), as identified, in the 18 websites selected.

$\begin{array}{llllllllllllllllll}\text { A } & \text { B } & \text { C } & \text { D } & \text { E } & \text { F } & \text { G } & \text { H } & \text { I } & \text { J } & \text { K } & \text { L } & \text { M } & \text { N } & \text { O } & \text { P } & \mathbf{Q} & \mathbf{R}\end{array}$

\section{Cautious sharing}

1. Protective

2. Sharing

Acquisition/Control/Ownership

1. Claiming and land use

2. Traditional naming

3. Returning - Documenting contested spaces Indigenized processes

1. Indigenous voiced: Self-generated content

2. Political: Bottom-up/grass roots processes

\section{Ethnographic/Cultural}

\section{Testimonials}

2a. Narrative storytelling

2b. Cultural narratives

2c. Traditional practices narrative

3. Survival narratives and documentation

\section{Critically reframing}

1. Deconstructive /anti-colonial

2. Counter paternalistic/self generated

3. Gendered

\section{Restorative}

1. Envisioning/future centred

2a. Spiritual wellbeing

2b. Emotional wellbeing

2c. Physical wellbeing

2d. Mental wellbeing

3a. Participatory planning

3b. Community-based resource management

3c. Crowdsourcing

$3 d$. Volunteered geographic information

4. Self-actualizing

\section{Proactive/change oriented}

1. Interventionist

2. Revitalizing/regenerative

3. Connective

4. Networking

None $=$ No Content

$M=\operatorname{Marg}(1-5$ incidents $)$

$\mathrm{H}=$ High $(6+$ incidents $)$

$\begin{array}{llllllllllllllllll}\mathbf{H} & \mathbf{H} & \mathbf{H} & \mathbf{H} & \mathbf{H} & \mathbf{H} & \mathbf{H} & \mathbf{H} & \mathbf{H} & \mathbf{H} & & \mathbf{H} & \mathbf{H} & \mathbf{H} & \mathbf{H} & \mathbf{H} & \mathbf{H} & \\ \mathbf{H} & \mathbf{H} & \mathbf{H} & \mathbf{H} & \mathbf{H} & \mathbf{H} & \mathbf{H} & \mathbf{H} & \mathbf{H} & \mathbf{H} & & \mathbf{H} & \mathbf{H} & \mathbf{H} & \mathbf{H} & \mathbf{H} & \mathbf{H} & \\ & & & & & & & & & & & & & & & & & \\ \mathbf{H} & \mathbf{H} & \mathbf{H} & \mathbf{H} & \mathbf{H} & \mathbf{H} & \mathbf{H} & \mathbf{H} & \mathrm{M} & \mathbf{H} & & & \mathbf{H} & \mathbf{H} & \mathbf{H} & \mathbf{H} & \mathbf{H} & \mathbf{H} \\ \mathbf{H} & \mathbf{H} & \mathbf{H} & \mathbf{H} & \mathbf{H} & \mathbf{H} & \mathbf{H} & \mathbf{H} & \mathrm{M} & \mathbf{H} & \mathbf{H} & \mathbf{H} & \mathbf{H} & \mathbf{H} & \mathbf{H} & \mathbf{H} & \mathbf{H} & \mathbf{H} \\ \mathbf{H} & \mathbf{H} & & \mathbf{H} & \mathbf{H} & \mathbf{H} & \mathbf{H} & & \mathrm{M} & & \mathbf{H} & & & \mathrm{M} & \mathbf{H} & & & \mathbf{H}\end{array}$

$\begin{array}{llllllllllllllll}\mathbf{H} & \mathbf{H} & \mathbf{H} & \mathbf{H} & \mathbf{H} & \mathbf{H} & \mathbf{H} & \mathbf{H} & \mathbf{H} & \mathbf{H} & \mathbf{H} & \mathbf{H} & \mathbf{H} & \mathbf{H} & \mathbf{H} & \text { M } \\ \mathbf{H} & \mathbf{H} & \mathbf{H} & \mathbf{H} & \mathbf{H} & \mathbf{H} & \mathbf{H} & \mathbf{H} & \mathbf{H} & & \mathbf{H} & \mathbf{H} & \mathbf{H} & & \mathbf{H} & \text { M }\end{array}$

$\begin{array}{llllllllllllll}\mathbf{H} & \mathbf{H} & \mathbf{H} & \mathbf{H} & \mathbf{H} & & \mathbf{H} & & \mathbf{H} & \mathbf{H} & \mathbf{H} & & & \\ \mathbf{H} & \mathbf{H} & \mathbf{H} & \mathbf{H} & \mathbf{H} & \mathbf{H} & \mathbf{H} & \mathbf{H} & \mathbf{H} & \mathbf{H} & \mathbf{H} & \mathbf{H} & & \text { H } \\ \mathbf{H} & \mathbf{H} & \mathbf{H} & \mathbf{H} & \mathbf{H} & \mathbf{H} & \mathbf{H} & \mathbf{H} & \mathbf{H} & \mathbf{H} & \mathbf{H} & \mathbf{H} & \mathbf{M} & \mathbf{H} \\ \mathbf{H} & \mathbf{H} & \mathbf{H} & \mathbf{H} & \mathbf{H} & \mathbf{H} & \mathbf{H} & \mathbf{H} & \mathbf{H} & \mathbf{H} & \mathbf{H} & \mathbf{H} & & \mathbf{H} \\ \mathbf{H} & \mathbf{H} & \mathbf{H} & \mathbf{H} & \mathbf{H} & \mathbf{H} & & \mathbf{H} & & & \mathbf{H} & & & \mathbf{H}\end{array}$

$\begin{array}{lllllllllllll}\mathbf{H} & \mathbf{H} & \mathbf{H} & \mathbf{H} & \mathbf{H} & \mathbf{H} & \mathbf{H} & \mathbf{H} & \mathrm{M} & \mathbf{H} & \mathbf{H} & \mathrm{M} & \mathrm{M}\end{array}$

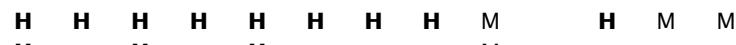

$\begin{array}{lllll}\mathbf{H} & \mathbf{H} & \mathbf{H} & \mathrm{M}\end{array}$

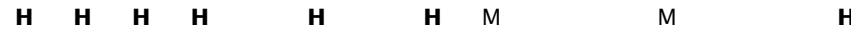

$\begin{array}{llllllllllll}\mathbf{H} & \mathbf{H} & \mathbf{M} & \mathbf{H} & \mathbf{H} & \mathbf{H} & \mathbf{H} & \mathbf{H} & \mathrm{M} & \mathbf{H} & \mathbf{H} & \mathrm{M}\end{array}$

$\begin{array}{llllllllllll}\mathbf{H} & \mathbf{H} & \mathrm{M} & \mathbf{H} & \mathbf{H} & \mathbf{H} & \mathbf{H} & \mathbf{H} & \mathrm{M} & \mathbf{H} & \mathbf{H} & \mathrm{M}\end{array}$

$\begin{array}{lllllllllll}\mathbf{H} & \mathbf{H} & \mathbf{M} & \mathbf{H} & \mathbf{H} & \mathbf{H} & \mathbf{H} & & & & \end{array}$

$\begin{array}{llllllllllll}\mathbf{H} & \mathbf{H} & \mathrm{M} & \mathbf{H} & \mathbf{H} & \mathbf{H} & \mathbf{H} & \mathbf{H} & \mathrm{M} & \mathbf{H} & \mathbf{H} & \mathrm{M}\end{array}$

H $M$

H $M$

H $\quad$ H $M$

$\begin{array}{lll}\text { H } & \text { H } & M\end{array}$

H $\quad$ H $M$

$\begin{array}{lll}\text { H } & \text { H } & \text { H }\end{array}$

$\begin{array}{llll}M & \text { H } & \text { H } & \text { M }\end{array}$

M

$\begin{array}{llll}\text { H } & \text { H } & \text { M } & \text { H }\end{array}$

$\begin{array}{lllllllll}\mathbf{H} & \mathbf{H} & \mathrm{M} & \mathbf{H} & \mathbf{H} & \mathbf{H} & \mathbf{H} & \mathbf{H} & \mathrm{M}\end{array}$

$\begin{array}{lllllllll}\mathbf{H} & \mathbf{H} & \mathrm{M} & \mathbf{H} & \mathbf{H} & \mathbf{H} & \mathbf{H} & \mathbf{H} & \mathrm{M}\end{array}$

$\begin{array}{lllllllll}\text { H } & \mathbf{H} & \mathbf{M} & \mathbf{H} & \mathbf{H} & \mathbf{H} & & \mathbf{H} & \mathrm{M}\end{array}$ 
The Native Land project is an interesting example of a very successful website launched in 2015 by a non-Indigenous individual, focusing on a highly sensitive topic: territories associated with different Indigenous communities in Canada and beyond. It became a not-for-profit organization in December 2018, with a board of directors comprising only members with an Indigenous background. Although this example may suggest that there is a growing presence of Indigenous people on Indigenous online mapping decision-making bodies, the issue of who controls what in these projects needs to be raised.

To address it, we first looked at who controlled the data collection process. This was assessed in our study with the meta-criterion "Indigenized process," which included two criteria: "selfgenerated" and "grassroots process." Content falling under the heading "self-generated" is used to identify incidences where the nascence of the website came directly from an Indigenous person, group, or community, while content counted under "grassroots process" is used more narrowly to identify content that featured or documented community-based bottom-up programs, activities, and events. Both criteria appear extensively in a vast majority of websites (i.e., value "H"), suggesting that Indigenous communities were responsible for initiating these projects and for producing content for most of these websites.

We then looked at who controls what parts of the information shared throughout these websites. Cautious sharing is indeed a vital issue with regard to Indigenous knowledge and territories, as illustrated by the two following comments:

A community in the Okanagan showed their sacred places; they made it public. Someone saw this, and someone went and found one of those sites, and they spray painted it black. They desecrated it. (P1: Indigenous, scholar, community activist)

Sometimes, when you put data on maps, different communities get upset ... Sometimes there are even issues about sharing information between nations. (P3: non-Indigenous person, cartographer, GIS technician)

In our analysis, we assessed the control of datasharing with the meta-criterion "cautious sharing." This meta-criterion includes two criteria- "protective" and "sharing" - that aim to identify information gatekeeping through the assessment of data sourcing. The study sites fell into two broad categories when it came to data sourcing. One category consisted of websites that are posting new content sourced to specific Indigenous persons or communities. In these instances, the content was counted as being "protectively" shared since it was controlled by an Indigenous gatekeeper. The second category consisted of websites "sharing" Indigenous content, primarily through re-posting of existing Indigenous shared materials to the site. Both of these criteria obtained the high scores among the 21 criteria, demonstrating the extensive control of Indigenous groups and individuals on the content shared throughout these different sites.

Overall it seems that Indigenous groups have been highly involved in most of the projects studied and have been controlling the data collection and data-sharing aspects of these projects. Where they seem to have less direct control is at the technological level. This is supported by Coleman (2019) who asserts that colonialism is alive and well in the digital realm. Coleman notes that tech companies that provide technology and infrastructure are predominantly Western-based, as are many of the web-based data harvesting and advertising companies. Western providers design technology and systems that ensure their foothold in and continued dominance of the technology ecosystem. Kwet (2019) supports these arguments by noting that digital colonialism is reinforced by the implementation of infrastructure and systems that enable Western-based providers.

All the websites reviewed have been designed in collaboration with non-Indigenous organizations and individuals that have overseen the technical aspects of these projects. Most of this technical expertise comes from academia (predominantly from the Geomatics and Cartographic Research Center at Carleton University and the Ethnographic Mapping Lab at the University of Victoria). Although the main discourse and philosophy of these academic partners is to share their expertise and tools with their Indigenous partners, they have their own academic agendas and requirements. Indigenous communities often do not have the necessary time and resources to maintain and develop these technological projects. In that sense, Indigenous online mapping projects remain highly dependent on external technological expertise and cannot be considered as fully decolonized. 


\section{Web maps are (more than) the shadows of GIS}

So, if I am going to express something with power, I am going to do it with whatever way I need to depending on the audience or who I want to listen to me. So, if I am mapping internally in a ceremonial situation, it has to be tools that are there in a good way, in a ceremonial way. Those are going to be different than the tools for expression that need to speak powerfully to the local newspaper or a federal funding agency or to people I don't know on the web. It's going to be whatever tools that are needed. (P9: Indigenous, scholar, cartographer)

This quote positions web mapping in a much broader set of Indigenous cartographic tools and practices. It is portraying web mapping, not as a set of tools that are inherently decolonizing or indigenizing, but rather a method or framework for decolonizing discourse. The participant's observation takes into consideration the ontology and the epistemology aspects of web mapping, viewing it as a vehicle for the advancement of a decolonizing or indigenizing agenda, as further discussed by this same participant below:

You go to these communities, and their tribal GIS offices will blow you away. They are running a government in a serious and sophisticated way using serious and credible cartographic tools with data that is very rich, and I think the kind of web maps that are appearing are just shadows of these really powerful systems that are fully resourced that the tribal offices are doing. (P6: nonIndigenous cartographer, anthropologist)

This prevalence of GIS over web-mapping projects can be explained by the longer involvement of Indigenous communities in the former, as well as by its higher relevance for territorial claims, as illustrated by the following comment:

I think before you go into building a web-based application, a web map, you have to really figure out what is the story you are trying to tell. The use and occupancy approach that we take and end up using is the method that says if this is going to go to court, we can stand by it. So, you are using a very rigorous methodology to go and collect that data for a very particular purpose. If I just go out and want to tell a story or talk about places, I might not use this rigorous scientific research method. (P1: Indigenous, scholar, community activist)

This quote emphasizes the evident relationship that exists between web mapping and storytelling, but it also implies that storytelling is somehow disconnected from land claims because it is not associated with "rigorous scientific" methods and, therefore, may not be convincing in a courtroom. The results of our review show a slightly different picture revealed by the high number of incidents associated with the criterion "claiming and land use." This criterion encompasses mentions of meaningful locations (e.g., kill sites, medicinal harvesting, and sacred spaces) that are used to demonstrate long-term occupation of territories of significance to Indigenous peoples. This criterion has been identified in almost all the websites reviewed, demonstrating the importance given to land claiming. While Indigenous groups have used GIS as a way to express their territorial concerns and claims in what is considered an acceptable form of expression in Western culture, online mapping applications are also used extensively for the same purpose but through a different form of expression, as discussed in the next section.

The importance of territorial claims as a significant issue is also illustrated by the high number of incidents related to "traditional naming." Traditional place naming is closely linked to territorial claims since it fundamentally challenges colonial narratives about history, identity, and tenure. The act of placing traditional names on the map is a de facto correction of the Western designations of sites and locations. In all of the websites studied, place names were written and/or mentioned in their original Indigenous language, and four of these websites are even fully dedicated to place naming: Kitikmeot Place Name Atlas, Gwich'in Place Names and Story Atlas, Stz'uminus Storied Places, and Squamish Atlas. Two other sites also include an important place-naming component: Pan Inuit Trails Map and Inuit Siku Atlas. In other words, about one-third of the 18 online atlases studied focus mainly or exclusively on place-name mapping, while almost all the other sites integrate some aspects of place naming as well.

Although it is possible to represent Indigenous place names thoughtfully on printed maps (see Pearce 2017), digital technologies open the 
possibility for linking these place names with their oral origins through audio/video files. Digital formats also offer different kinds of options for contextualizing these place names, their meanings, and the stories associated with them, which are often at least as important as the place name itself (Pearce 2008). In this sense, online mapping's potential for naming places and mapping place names has been extensively used in these websites as a way to contribute to reclaiming cultural and territorial heritage.

\section{Online mapping to tell and listen to Indigenous stories}

Stories appear in the vast majority of the websites studied. These stories range from video footage on The "Oka Crisis": A Digital Atlas of the 1990 Events at Kanehsatà:ke to the stories of elders like Eunice Mitchell on the Gwich'in Place Names Atlas, who talks about travelling with her family and the place names and stories she learned along the route. Although elders often tell stories, there is a growing recognition of the importance of recording and mapping stories from Indigenous youths. One of the strengths of online mapping is its ability to showcase such stories for strategic reasons. For example, as one interview participant put it, stories "prove we are still occupying and using this land" (Interview participant \#3 sec. 2:3 Indigenous person, female, community worker, and amateur cartographer). Here again, stories appear to be deeply linked to territorial claims, but they can serve other purposes such as intergenerational links as illustrated in the Views from the North Atlas (http:// viewsfromthenorth.ca), where on-the-ground data gathering and recording was done by youth working directly with elders in their communities.

Looking closely at the different traits related to narratives, the one called "cultural narratives" is linked to stories about hunting, gathering, food preparation, kill sites, medicinal plants, and Indigenous spirituality. These kinds of cultural narratives appear on more websites than the two other types of narratives: "testimonials" and "survival narratives." "Testimonials" refer to content that is about personal experiences and the lasting impacts they have had on an individual. "Survival narratives" are defined as everyday stories about day-to-day life and land. Smith (2013) notes a distinction between testimony and other types of storytelling, namely that testimony has a more formal character. It is truth under oath, the voice of a witness, a monologue coming from a place of respect and protection, and has a sense of urgency and immediacy. For instance, The "Oka Crisis": A Digital Atlas of the 1990 Events at Kanehsatà:ke includes a reflection section looking back at the crisis from 25 years later with comments such as, "What sticks out in my mind, for sure, is having a concussion grenade thrown at me by a member of the SWAT team just before they came in. I remember choking on tear gas and being shot at. I remember being shot at by the army on September 1st" (Ethnographic Mapping Lab 2019). Although testimonial and survival narratives such as this one are slightly less common than cultural narratives, they are common enough to exemplify the legacy of these violent and traumatic events in contemporary Indigenous memories and the potential of online mapping applications for sharing these specific memories.

The extensive presence of different forms of narratives in these websites also contributes to rethinking the relationships between maps, places, and stories. Stories, which can be considered as the most appropriate form of spatial expression in Indigenous cultures, should take a more central role than maps, which can be considered as the most appropriate form of spatial expression in Western cultures. For instance, in the Húỷat website (Heiltsuk Nation 2019) - which was not reviewed in this project-Indigenous relationships with places are expressed throughout a combination of noncartographic media, specifically $360^{\circ}$ interactive photos of specific places on the Heiltsuk territory, tagged with video and audio files telling different stories about each place. This combination of media and $360^{\circ}$ interactive photos offers a more direct expression of Indigenous worldviews and perspectives than a conventional map would do. The interactive map in this project plays a marginal role here, which is simply to guide the user through the navigation between the different sites and the different media. In this type of project, the map is at the service of the stories, which may be considered as one aspect of decolonized mapping (Figure 3).

\section{Women's voices in Indigenous online mapping}

One last result we want to discuss in this paper concerns the overall unbalanced gender 

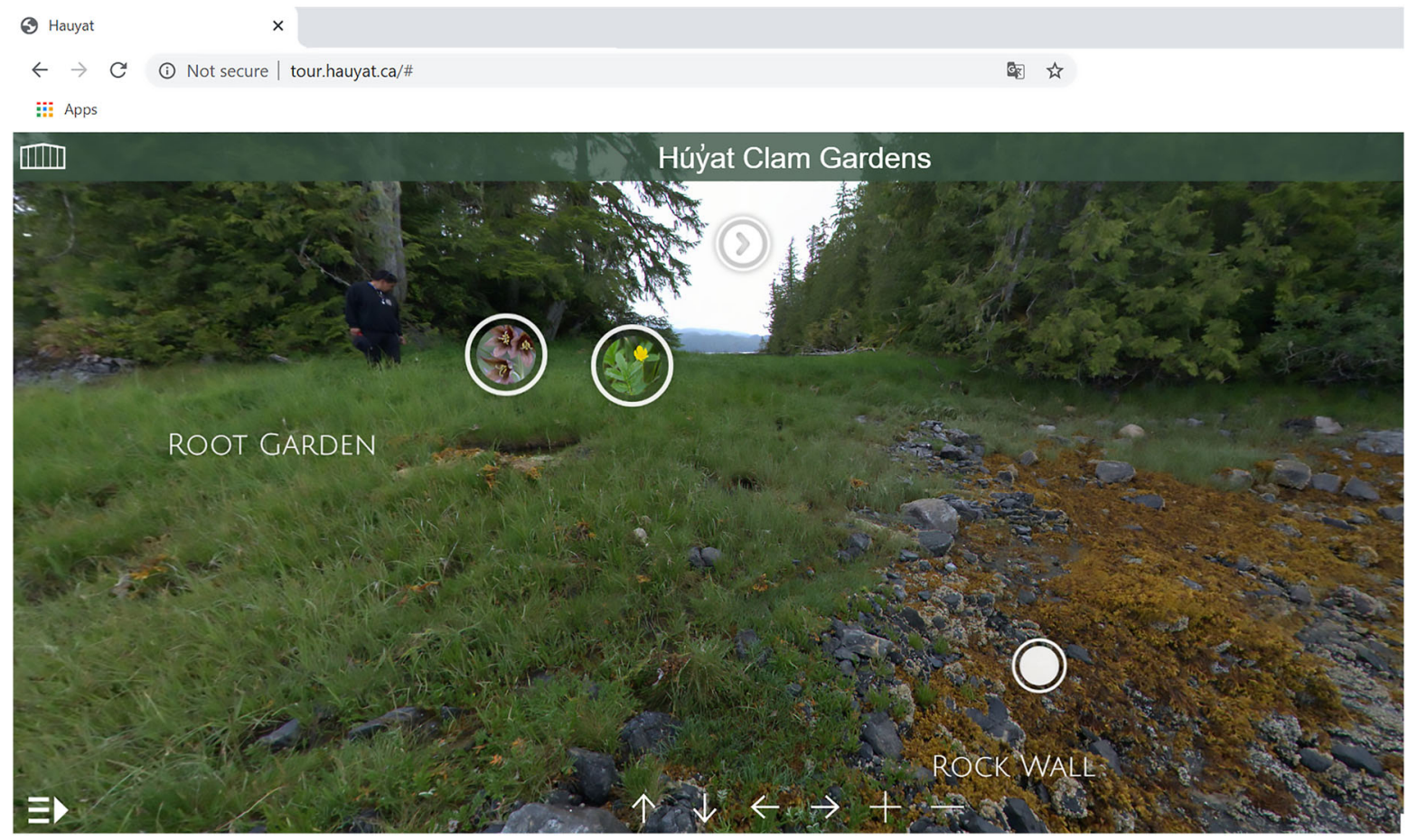

\section{Figure 3}

Screen capture of a $360^{\circ}$ interactive photo of a specific place on the Heiltsuk territory with embedded media that tell stories about this place. SOURCE: http://tour.hauyat.ca/\#.

perspectives conveyed by most of these websites. Women's perspectives remain marginal in these websites as characterized by the criterion "Gendered" that appears as " $\mathrm{H}$ " in only three of the websites reviewed. This criterion was used to identify every instance involving women's perspectives, such as women's voices and women's activities. Besides a few examples such as Views from the North Atlas and the Siku Sea Ice Atlas that feature the voices of women as both participants and researchers, there is an apparent gender imbalance in the content of the websites studied.

A combination of factors could explain this general lack of women's perspective. The first factor is the historical focus of Indigenous and Western mapping on the practicality of travelling-a male-dominated activity. The second factor is the tactical focus on mapping male activities such as hunting since these activities often encompass a significant territory and could be useful strategically for claiming large pieces of land. The third factor is the marginal role often played by women in the participatory mapping context as illustrated by this comment:

Well, the people giving the information were women, and the people with the tools were men ... So, if we are talking about participatory mapping projects, I have been struck by how many times I see a photograph of a participatory mapping project, globally, it's predominantly men in the picture. Occasionally women, and if women are present, they are in the back row. I think people are more aware of that or trying to become more aware of that. (P9: Indigenous, scholar, cartographer)

The fourth factor is the general lack of space occupied by women in technology-oriented activities such as GIS and mapmaking (Dempsey 2014). This lack of space has led to, or is the result of, the expression of female voices through other means than maps-as illustrated by the following comment from the previous participant:

Mapping as it is defined academically is highly gendered and predominantly male. How many native 
women, it strikes me, are strong voices in scholarship on literature and story. I don't know if you have seen Mishuana Goeman's book Mark My Words? She writes about how she wanted to map histories and map intersections of knowledge of native people and how she can do that in a woman's way. And, to do that in a woman's way, she did that through words. (P9: Indigenous, scholar, cartographer)

This idea is supported by a comment from another interviewee who suggested that film is perhaps a better format than maps for expressing women's voices and how salient women's voices were in campaigns of recovery. One example is Abenaki film director Alanis Obomsawin, who uses films and maps in films to propose an alternative perspective on the geography of Canada (Remy 2018).

Although certain Indigenous women's voices may be better expressed through words and films, some clear and powerful ones have also been expressed through mapping practices over the last few decades. For example, the voices of Margaret Wickens Pearce and Renee Pualani Louis have been influential in making Indigenous mapping heard and seen, while new voices such as Annita Lucchesi's are also starting to redraw the contours of decolonial mapping. Lucchesi is involved in various mapping projects, including the mapping of murdered and missing Indigenous women in the United States and Canada. In a recent paper, she compares decolonial mapping with "women warriors," as described by Ojibwe female writer Lois Beardslee.

Like these women warriors, decolonial mapping can easily navigate in and out of colonial academic and aesthetic norms. It is only concerned with these standards and expectations when necessary and strategic. It can soothe settlers' consciences, and also be abrasive, confrontational, or refuse to engage with them altogether.... Decolonial mapping is a product of carefully maintained gems shared by aunties and grandmothers at coming of age and healing ceremonies, in longhouses, at kitchen tables, in cups of tea made just like her grandmother did, during rides home from the casino, in the books they fought to leave for us in libraries and archives. (Lucchesi 2018, 19-20)

Decolonial mapping cannot be fully achieved without the clear and strong involvement of women. Although this involvement remains somehow marginal according to the gender imbalance identified in the websites reviewed here-as well as in the embarrassing gender imbalance in the individuals we interviewed for this projectthere are pieces of evidence that things are changing. Indigenous women have been the driving force behind the mapping of missing and murdered Indigenous women (Cook and Himmelman 2018); young Indigenous women occupy three of the four positions on the brand new board of directors of the native-land mapping project; four out of the six guest speakers of the 2018 Indigenous Mapping Workshop organized by the Firelight group were also young Indigenous women. Although women's voices remain underrepresented in the projects reviewed, there are realistic hopes that these voices are going to become more and more influential in the movement towards decolonized Indigenous mapping.

\section{Conclusion}

Beyond the different results presented and discussed in this paper, this journey through Indigenous online mapping projects in Canada allowed us to appreciate multiple aspects of contemporary Indigenous mapping. The "Unity race" mapped in the Voice of the Land Atlas raises awareness about issues related to violence within and between communities. The Siku Sea Ice Atlas showcases a rich and diverse multimedia content related to ice conditions. The Gwich'in Atlas exemplifies the potential of online atlases for archiving and communicating place names and the stories they are associated with. The Stz'uminus Storied Places Digital Atlas provides a compelling example of a mapping process that supports intergenerational communications and connectivity. The Two Houses Half-Buried Atlas demonstrates that online mapping applications can convey highly emotional memories of destruction, such as the ones of the Hul'qumi'num peoples in British Columbia in the 1930s. The interactive mapping of place names and ancestral routes in the Pan Inuit Trails Map makes visible the long history of the extensive occupation of the land by Indigenous peoples. Finally, the Native Land project clearly challenges the concept of terra nullius by offering the viewer a 
representation of Turtle Island wholly covered by a mosaic of Indigenous cultures, territories, and languages.

Overall, these projects demonstrate the diversity of possibilities in terms of online mapping and digital technologies mobilized by Indigenous communities and their partners, to continuing reclaiming Indigenous people's rights to the land as well as their unique cultural heritage. At the end of this review, it is clear that online mapping is not inherently decolonial, but what is even more apparent is that Indigenous communities across Canada have been embracing its potential to make it part of a decolonial agenda.

\section{Acknowledgements}

This research has been made possible with the financial support of the Social Sciences and Humanities Research Council of Canada (SSHRC). We would also like to extend our gratitude to the ten individuals interviewed in the context of this project.

\section{References}

Attwood, B. 2004. The law of the land or the law of the land?: History, law and narrative in a settler society. History Compass 2(1): 1-30.

Banner, S. 2005. Why terra nullius? Anthropology and property law in early Australia. Law and History Review 23(1): 95-131.

Borrows, J. 2015. The durability of terra nullius: Tsilhqot'in Nation v. British Columbia. UBC Law Review 48(3): 701-742.

Bryan, J., and D. Wood. 2015. Weaponizing maps: Indigenous peoples and counterinsurgency in the Americas. New York, NY: Guilford Press.

Cameron, E. 2011. Copper stories: Imaginative geographies and material orderings of the Central Canadian Arctic. In Rethinking the great white North: Race, nature and the historical geographies of whiteness in Canada, ed. A. Baldwin, L. Cameron, and A. Kobayashi. Vancouver BC: UBC Press, 169-190.

Caquard, S., S. Pyne, H. Igloliorte, K. Mierins, A. Hayes, and F. Taylor. 2009. A "living" atlas for geospatial storytelling: The Cybercartographic Atlas of Indigenous Perspectives and Knowledge of the Great Lakes region. Cartographica: The International Journal for Geographic Information and Geovisualization 44(2): 83-100.

Cavanagh, E. 2014. Possession and dispossession in corporate New France, 1600-1663: Debunking a "juridical history" and revisiting terra nullius. Law and History Review 32(1): 97-125.

CBC (Canadian Broadcasting Corporation). 2017. Indigenous communities in Canada finally on Google Maps. https://www. cbc.ca/news/canada/manitoba/indigenous-communitiesmap-1.4169515

Coleman, D. 2019. Digital colonialism: The 21st century scramble for Africa through the extraction and control of user data and the limitations of data protection laws. Michigan Journal of Race and Law 24(2): 417-439.
Cook, J., and Himmelman, I. 2018. You probably never heard about these 500 missing and murdered women. https://www. huffingtonpost.ca/entry/missing-murdered-native-women_ n_5beb0e48e4b044bbb1a99db0

Corbett, J., M. Evans, G. Legault, and Z. Romano. 2015. Relocating a sense of place using the participatory Geoweb: The historical document database of the Métis nation of British Columbia. International Journal of Applied Geospatial Research 6(1): 24-38.

Cunsolo Willox, A., S. Harper, and V. Edge, 'My Word': Storytelling \& Digital Media Lab, and Rigolet Inuit Community Government. 2013. Storytelling in a digital age: Digital storytelling as an emerging narrative method for preserving and promoting indigenous oral wisdom. Qualitative Research 13(2): 127-147.

Dempsey, C. 2014. Gender in the GIS workforce. GIS Lounge https://www.gislounge.com/gender-gis-workforce/

DeRoy, S. 2016. Direct-to-digital mapping methodology: A handson guidebook for applying Google Earth. The Firelight Group. https://firelight.ca/wp-content/uploads/2016/04/Guide_ FirelightGroup_DirectToDigital_20JAN2016.pdf

Drawson, A., E. Toombs, and C. Mushquash. 2017. Indigenous research methods: A systematic review. International Indigenous Policy Journal 8(2): 1-25.

Eades, G. 2015. Maps and memes: Redrawing culture, place, and identity in Indigenous communities. Montreal, QC: McGillQueen's Press.

Eglinton, K., A. Gubrium, and L. Wexler. 2017. Digital storytelling as arts-inspired inquiry for engaging, understanding, and supporting Indigenous youth. International Journal of Education \& the Arts 18(5): 1-29.

Ethnographic Mapping Lab. 2019. "Oka Crisis": A digital atlas of the 1990 events at Kanehsatà:ke. https://www.uvic.ca/ socialsciences/ethnographicmapping/projects/oka/index.php

Heiltsuk Nation. 2019. Húyat: Our voices, our land. Heiltsuk Integrated Resource Management Department Board. http:// www.hauyat.ca/index.html

Hunt, D., and S. A. Stevenson. 2017. Decolonizing geographies of power: Indigenous digital counter-mapping practices on Turtle Island. Settler Colonial Studies 7(3): 372-392.

de Jager, A., A. Fogarty, A. Tewson, C. Lenette, and K. Boydell. 2017. Digital storytelling in research: A systematic review. The Qualitative Report 22(10): 2548-2582.

Kwet, M. 2019. Digital colonialism: US empire and the new imperialism in the Global South. Race \& Class 60(4): 3-26.

Louis, R. 2007. Can you hear us now? Voices from the margin: Using indigenous methodologies in geographic research. Geographical Research 45(2): 130-139.

Louis, R., J. Johnson, and A. Pramono. 2012. Introduction: Indigenous cartographies and counter-mapping. Cartographica: The International Journal for Geographic Information and Geovisualization 47(2): 77-79.

Lucchesi, A. 2018. "Indians don't make maps": Indigenous cartographic traditions and innovations. American Indian Culture and Research Journal 42(3): 11-26.

McIvor, O. 2010. I am my subject: Blending Indigenous research methodology and autoethnography through integrity-based, spirit-based research. Canadian Journal of Native Education 33(1): 137-151.

Olson, R., J. Hackett, and S. DeRoy. 2016. Mapping the digital terrain: Towards Indigenous geographic information and spatial data quality indicators for Indigenous knowledge 
and traditional land-use data collection. The Cartographic Journal 53(4): 348-355.

Pearce, M. W. 2008. Framing the days: Place and narrative in cartography. Cartography and Geographic Information Science 35(1): 17-32.

- 2017. Coming home to Indigenous place names in Canada. Canadian-American Center. https://umaine.edu/canam/ publications/coming-home-map/

Pearce, M., and R. Louis. 2008. Mapping indigenous depth of place. American Indian Culture and Research Journal 32(3): 107-126.

Pyne, S. 2020. Cybercartography, emergence and iterative development: The Residential Schools Land Memory Project (RSLMMP). In Modern cartography series, ed. S. Pyne and F. Taylor. Cambridge, MA: Academic Press, 31-56.

Pyne, S., and F. Taylor. 2012. Mapping Indigenous perspectives in the making of the Cybercartographic Atlas of the Lake Huron Treaty Relationship Process: A performative approach in a reconciliation context. Cartographica 47(2): 92-104.

Reid, G., and R. Sieber. 2019. Do geospatial ontologies perpetuate Indigenous assimilation? Progress in Human Geography https://doi.org/10.1177/0309132518824646

Remy, L. 2018. Making the map speak: Indigenous animated cartographies as contrapuntal spatial representations. NECSUS. European Journal of Media Studies 7(2): 183-203.

Reynolds, H. 2003. The law of the land. Ringwood, Australia: Penguin Books.
Rundstrom, R. 1991. Mapping, postmodernism, indigenous people and the changing direction of North American cartography. Cartographica: The International Journal for Geographic Information and Geovisualization 28(2): $1-12$.

Sletto, B. 2014. Cartographies of remembrance and becoming in the Sierra de Perijá, Venezuela. Transactions of the Institute of British Geographers 39(3): 360-372.

Smith, L. 2013. Decolonizing methodologies: Research and indigenous peoples. London, UK: Zed Books Ltd.

Thom, B., B. Colombi, and T. Degai. 2016. Bringing indigenous Kamchatka to Google Earth: Collaborative digital mapping with the Itelmen peoples. Sibirica 15(3): 1-30.

Turnbull, D. 2008. What is cartographic rationality? Metascience $17(2): 215-224$

Usher, P. 2003. Environment, race and nation reconsidered: Reflections on Aboriginal land claims in Canada. The Canadian Geographer 47(4): 365-382.

Vermeylen, S., G. Davies, and D. van der Horst. 2012. Deconstructing the conservancy map: Hxaro, n!ore, and rhizomes in the Kalahari. Cartographica: The International Journal for Geographic Information and Geovisualization 47(2): 121-134.

Wainwright, J., and J. Bryan. 2009. Cartography, territory, property: Postcolonial reflections on indigenous countermapping in Nicaragua and Belize. Cultural geographies 16(2): 153-178. 